\title{
Recreational scuba diving: negative or positive effects of oxidative and cardiovascular stress?
}

\author{
Antonija Perovic ${ }^{* 1}$, Adriana Unic ${ }^{2}$, Jerka Dumic ${ }^{3}$ \\ 'Department of Biochemical and Hematological Laboratory Diagnostics, Dubrovnik General Hospital, Dubrovnik, Croatia \\ ${ }^{2}$ Clinical Department of Laboratory Diagnostics, Dubrava University Hospital, Zagreb, Croatia \\ ${ }^{3}$ University of Zagreb, Faculty of Pharmacy and Biochemistry, Department of Biochemistry and Molecular Biology, Zagreb, Croatia \\ *Corresponding author: antonija.perovic@email.t-com.hr
}

\begin{abstract}
Environmental conditions and increased physical activity during scuba diving are followed by increased production of free radicals and disturbed redox balance. Redox balance disorder is associated with damage of cellular components, changes of cellular signaling pathways and alterations of gene expression. Oxidative stress leads to increased expression of sirtuins (SIRTs), molecules which play an important role in the antioxidant defense, due to their sensitivity to the changes in the redox status and their ability to regulate redox homeostasis. These facts make SIRTs interesting to be considered as molecules affected by scuba diving and in that sense, as potential biomarkers of oxidative status or possible drug targets in reduction of reactive oxygen species (ROS) accumulation. In addition, SIRTs effects through currently known targets make them intriguing molecules which can act positively on health in general and whose expression can be induced by scuba diving.

A demanding physical activity, as well as other circumstances present in scuba diving, has the greatest load on the cardiovascular function (CV). The mechanisms of $\mathrm{CV}$ response during scuba diving are still unclear, but diving-induced oxidative stress and the increase in SIRTs expression could be an important factor in $\mathrm{CV}$ adaptation. This review summarizes current knowledge on scuba diving-induced oxidative and $\mathrm{CV}$ stress and describes the important roles of SIRTs in the (patho)physiological processes caused by the redox balance disorder.
\end{abstract}

Key words: diving; oxidative stress; sirtuins; cardiovascular system

\section{Introduction}

In the last few decades, diving with the self contained underwater breathing apparatus (scuba) has become a popular recreational sport activity all around the world. Sport or recreational scuba diving means diving to a depth of not more than 40 meters, using only compressed air or nitrox (mixture of nitrogen and oxygen) with no more than $40 \%$ oxygen as a breathing gas and having a direct vertical access to the surface, without decompression stop. As opposed to recreational scuba diving and its limits, technical scuba diving is more complex and usually requires mandatory decompression stop on surfacing and/or using of multiple gas mixtures such as trimix (mixture of nitrogen, oxygen and helium), heliox (mixture of helium and oxygen) or hydrox (mixture of hydrogen and oxygen) as breathing media (1).

The effects of scuba diving on health are reflected through the oxidative stress which may be caused by demanding physical activity, hyperoxia and exposure to cold temperatures. Furthermore, other circumstances present in diving such as the formation of intravascular bubbles, the effect of immersion, high pressure environment, together with the aforementioned factors have the greatest load on the cardiovascular function (CV). 
The aim of this review is to summarize the current knowledge of scuba diving effects on oxidative stress and CV function, highlighting the role of sirtuins (SIRTs) in the oxidative status in order to improve understanding of their potential role in the (pato)physiological processes in scuba divers.

\section{Effects of scuba diving on the oxidative status}

An imbalance between the free radical production and antioxidant defence in human body leads to an oxidative stress state. The negative effects of oxidative stress are associated with the pathophysiology of many diseases and aging. They are the consequence of a reduction in resistance to oxidative stress with aging and the accumulation of free radicals. Physical exercise can also increase oxidative stress and cause disruption of redox homeostasis. However, many studies have shown a beneficial role of the reactive oxygen species (ROS) produced during exercise, which leads to important training adaptations: an increase in resistance to oxidative stress, angiogenesis, mitochondria biogenesis, and muscle hypertrophy (2).

It is well established that exercise can have both positive and negative effects on oxidative status depending on exercise load, exercise specificity and the basal level of physical condition. However, the effect of scuba diving on the ROS production and oxidative stress resistance compared to other recreational activities is still unknown. Furthermore, it remains unclear in which circumstances the practice of scuba diving can be helpful or harmful.

Looking for the potential molecules which could be effective in the increase of the resistence to the oxidative stress and thus for the extension of life span, led to the discovery of the new compounds called anti-aging molecules or sirtuins, enzymes sensitive to the increased ROS production $(3,4)$. SIRTs, as sensors of the oxidative stress level as well as important molecules in antioxidant defense, could provide answers to the previously mentioned concerns. Unfortunately, to date there is no data about scuba dive influence on SIRTs expression.
Due to the weight of the diving equipment and increased resistance to movement, scuba diving is a demanding physical activity. Furthermore, divers are exposed to the changes in environmental conditions that are not usually present in other types of physical activity. Besides underwater pressure and cold temperatures, these changes also include breathing oxygen at the elevated pressure and increased resistance to breathing (5). Intensified physical activity and coldness can lead to the increased production of free radicals. Additionally, hyperoxia as a result of the hyperbaric exposure during diving and breathing oxygen at high pressure could induce oxidative stress (6).

The current data on influences of scuba diving on oxidative status is controversial; while some studies describe positive effects, others suggest undesirable consequences of scuba diving on human health. The main reason for such ambiguous results lays in the fact that the studies were conducted under different conditions, including differences in selection of evaluated biomarkers of oxidative status, and the time and method of determination.

Ferrer et al. studied the effects of the single scuba diving episode and hyperbaric oxygen (HBO) treatment in a hyperbaric chamber, on the lymphocyte hydrogen peroxide production $\left(\mathrm{H}_{2} \mathrm{O}_{2}\right)$ and lymphocyte antioxidant system. While $\mathrm{H}_{2} \mathrm{O}_{2}$ production, glutathione peroxidase (GPx) and catalase (CAT) activities were increased after diving, following $\mathrm{HBO}$ exposure only the increase in $\mathrm{H}_{2} \mathrm{O}_{2}$ production and GPx activity was reported (6). These results suggest that hyperoxia associated to both scuba diving and HBO treatment leads to the condition of oxidative stress, yet it seems that diving influences the antioxidant defence in lymphocytes differently, comparing to hyperbaria at resting state. It is possible that physical activity during scuba diving contributes to the activation of antioxidant defence.

Another study showed that single scuba diving immersion, at a depth of $\mathbf{4 0}$ meters of sea water (msw), leads to an increase of erythrocytes GPx activity, plasma superoxide dismutase (SOD) and CAT activities, whilst the markers of oxidative damage, 
malondialdehyde (MDA) and protein carbonyl derivates, in both erythrocytes and plasma remained unchanged (7). According to these data, scuba dive to a depth of 40 msw leads to an antioxidant response in plasma and erythrocytes without the appearance of cellular damage. On the other hand, study on a single dive to a depth of 50 msw has found significant increase of plasma MDA 3 hours after diving. This study also revealed an increase in plasma CAT activity (immediately after diving) and plasma extracellular SOD protein levels (3 hours after diving), thus supporting the theory of the antioxidant activation during diving (8). The controversial results in MDA levels are probably the consequence of the sampling time after diving, the differences in the used test or differences between the participants. However, it is also possible that the differences in diving depths may have effect on MDA levels. The former supports the limitation of depth (40 meters) for recreational scuba diving.

It should be emphasized that there is no data on the effects of successive recreational scuba diving on oxidative status, whereas the results of studies on successive deep dives are also insufficient and unclear. Obad et al. reported a significantly increased level of oxidative stress (assessed by thiobarbituric acid-reactive substances (TBARS) method) and a tendency for plasma antioxidant capacity $(A O C)$ reduction after six trimix dives (55 to 80 msw), in six consecutive days (9). However, in another study, Vince et al. did not find the increase of lipid peroxidation (assessed by TBARS measurement) after simulated scuba dives in the hyperbaric chamber (10). Possible reasons for the discrepancy between these results are effects of immersion, exercise, temperature, resistance to breathing and psychological stress, which are present in underwater diving, or other factors such as the study population, timing of TBARS measurement etc.

Bearing in mind that recreational dives are often practiced consecutively (e.g. 4-5 dives in a row weekly) and that some divers do not comply with the depth limits of recreational diving, it is an important question whether activation of the antioxidant defence is fast and sufficient enough to prevent the accumulation of free radicals and the subsequential damage. Additional studies on the influence of diving on biomarkers of oxidative damage are certainly needed, especially at different depths of diving and with the practice of successive dives.

It is interesting to observe that some interventions before, during, and after scuba diving can affect the outcome of oxidative stress, CV changes that were observed after diving as well as intravascular bubbles formation. Morabito et al. has investigated the effect of the pre-dive breathing $100 \%$ oxygen at the different depths ( $0 \mathrm{msw}, 6 \mathrm{msw}, 12 \mathrm{msw}$ ) on the oxidative status and reported that in-water pre-breathing oxygen in particular at 12 msw, may enhance lymphocyte antioxidant activity and reduce ROS levels after diving (11). These data suggest that although breathing 100-percent oxygen at higher pressure may increase the ROS production, it also plays an important role in the lymphocyte adaptation to the oxidative stress.

Another study tested the effects of acute antioxidant supplementation on arterial endothelial function, pulmonary artery pressure and heart function before and after diving. It was shown that acute antioxidant treatment with vitamins $\mathrm{C}$ and $\mathrm{E}_{\text {, }}$ 2 hours before diving, reverses brachial endothelial dysfunction, while reduction in heart and pulmonary artery function were unchanged (12). The same authors reported that long-term antioxidant treatment reduces the endothelial dysfunction in divers (13). Diving-induced asymptomatic reduction of the endothelial function was observed in the several studies $(9,14,15)$. However, the causes which lead to the changes in the endothelial function are not entirely clear. The effect of antioxidant supplementation before diving supports the theory that ROS formed during dive have a role in the post-dive arterial endothelial dysfunction. Similarly to this hypothesis, antioxidant supplementation such as $\alpha$-lipoic acid (LA) has been proposed as an adjuvant to attenuate harmful ROS effects during HBO therapy for the treatment of a variety of conditions (16).

Furthermore, Dujic et al. demonstrated that a single bout of strenuous exercise, 24 hours before the simulated dive, ameliorates venous post-dive bubble formation (17). Another two studies by the 
same authors have shown that exercising during a decompression stop, and post-dive exercising reduce gas bubble formation after an open sea dive $(18,19)$. The above results are important for reducing the risk of diving decompression sickness (DCS). In addition, post-dive gas bubbles are one of the possible causes of arterial endothelial dysfunction. However, data on biomarkers of oxidative stress in such studies are still lacking.

Therefore, it is obvious that oxidative status changes are related to scuba diving, but the mechanisms of activation and expression of antioxidant enzymes, as well as their efficiency, remain elusive. SIRTs, as major contributors of antioxidative defence, are becoming a challenge in further investigations of positive and negative effects of oxidative stress.

\section{The role of sirtuins in oxidative status}

Because of their role in regulation of redox homeostasis SIRTs, a class III HDACs (histone deacetylases) which consist of seven members (SIRT1-7) represent intriguing molecules associated to different conditions that accompany ROS formation, including scuba diving. SIRTs proteins are nicotinamide adenine dinucleotide (NAD) dependent deacetylases. Therefore, the requirement of the NAD cofactor and the localization of some SIRTs have suggested that histones are not their primary targets. It is believed that SIRTs play an important role in the aging process and many aging-related diseases such as diabetes, cardiovascular, neurodegenerative, respiratory and autoimmune diseases as well as cancer. It is also considered that the identification of drugs and the nutrients which can increase SIRTs expression or activation may be a promising strategy to alleviate diseases associated with the accumulation of free radicals and aging. The beneficial lifespan effect of SIRTs is associated with their many biological functions directly or indirectly linked to aging and, in particular, due to their sensitivity to the changes in the redox status and their ability to regulate redox homeostasis (20). That is the reason why it is intriguing to consider SIRTs as molecules affected by scuba diving and in that sense, as potential biomarkers of oxida- tive status or possible drug targets in reduction of ROS accumulation.

SIRT1 is the most extensively studied among the sirtuin family members and along with SIRT3 plays an important role in expression and activation of antioxidant enzymes. Redox targets whose activity is regulated by SIRT1 include p53 (21) and forkhead box O (FOXO) transcription factor family (22). SIRT1 deacetylates p53 and thus reduces its transcriptional activity and preventing the induction of a p53-mediated apoptosis program (23). With increased levels of intracellular ROS, SIRT1 deacetylates and activates FOXO3a-mediated upregulation of CAT and SOD2 gene expression, leading to reduction of ROS levels. However, it is considered that SIRT1 has a dual role; while low levels of ROS lead to the SIRT1-mediated upregulation of FOXO3a and p53, higher levels lead to the switch to FOXO3a and p53 mediated apoptosis. Thus, SIRT1 acts as a ROS sensor which, depending on the severity of oxidative stress, induces protective mechanisms or mechanisms of apoptosis (24).

SIRT1 is the most widely characterized protein in the sirtuin family, and therefore a great deal of information regarding its role has been collected over the last decade. Its effects on the so far discovered targets and binding partners make it an interesting molecule, whose expression can be induced by scuba diving and therefore positively affect health in general. Table 1 summarizes some of SIRT1 targets and binding partners, and significance of SIRT1 action to them (21-39).

SIRT3 is a major mitochondrial deacetylase and plays a relevant role in energy metabolism and ATP-production. In addition to the mitochondrial signaling, SIRT3, as well as SIRT1, deacetylates FoxO3a transcription factor thus leading to the increased expression of CAT and SOD2, and consequently suppression of ROS levels (40). Furthermore, SIRT3 also has an important role in the activation of SOD2 (41) and through its numerous mitochondrial targets, increases activity of other antioxidant enzymes indirectly, by production NADPH (42). According to the above mentioned, it seems that SIRT3 is faster and more powerful in the antioxidant defence in relation to the SIRT1, 
TABLE 1. Possible effects of oxidative stress-induced SIRT1 expression through some of SIRT1 targets and binding partners.

\begin{tabular}{|c|c|c|}
\hline $\begin{array}{l}\text { SIRT1 targets and } \\
\text { binding partners }\end{array}$ & Significance of SIRT1 action & Reference; year \\
\hline $\mathrm{p} 53^{*}$ & $\begin{array}{l}\text { Preventions or inductions of apoptosis } \rightarrow \text { controlling resistance to oxidative } \\
\text { stress. }\end{array}$ & $\begin{array}{l}\text { Shah et al. (21); } 2012 . \\
\text { Luo et al. (23); } 2001 . \\
\text { Webster et al. (24); } 2012 .\end{array}$ \\
\hline $\begin{array}{l}\text { FOXO1* } \\
\text { FOXO3a* } \\
\text { FOXO4* }\end{array}$ & $\begin{array}{l}\text { Regulating genes involved in cellular catabolism, cell growth, proliferation, } \\
\text { differentiation, renewal, immune response and apoptosis } \rightarrow \text { increase } \\
\text { autophagic activities, preventing inflammation, controlling resistance to } \\
\text { oxidative stress. }\end{array}$ & $\begin{array}{l}\text { Ng et al. (22); } 2013 . \\
\text { Webster et al. (24); } 2012 .\end{array}$ \\
\hline PGC-1 $a^{*}$ & $\begin{array}{l}\text { Induction of gene expression for gluconeogenesis, mitochondrial fatty acid } \\
\text { oxidation, and mitochondrial biogenesis. }\end{array}$ & Nemeto et al. (25); 2005. \\
\hline NFKB* & Suppression of pro-inflammatory genes $\rightarrow$ preventing excessive inflammation. & Kauppinen et al. (26); 2013. \\
\hline HIF1a* & Repression of transcriptional activity. & Webster et al. (24); 2012. \\
\hline HIF2a* & Activation of transcriptional activity $\rightarrow$ increase erythropoietin. & Webster et al. (24); 2012. \\
\hline $\begin{array}{l}\text { Histone } 1^{*} \\
\text { Histone } 3^{*} \\
\text { Histone } 4^{*}\end{array}$ & $\begin{array}{l}\text { Impact on the formation and stability of chromatin, chromatin remodelling, } \\
\text { DNA repairs } \rightarrow \text { genomic stability, cellular longevity. }\end{array}$ & Baur (27); 2010. \\
\hline Cortactin* & Retards cancer cell motility and migration. & Tang (28); 2010. \\
\hline Ku70* & Promotes DNA repair activity $\rightarrow$ increases cell survival. & Jeong et al. (29); 2007. \\
\hline PPAR $\neq$ & $\begin{array}{l}\text { Suppression of genes involved in fat storage = reduction lipogenesis / } \\
\text { activation lipolysis. }\end{array}$ & Baur (27); 2010. \\
\hline PPARa $\neq$ & $\begin{array}{l}\text { Induction of genes involved in fatty acid uptake and oxidation, suppression of } \\
\text { glycolysis in the liver. }\end{array}$ & Baur (27); 2010. \\
\hline UCP2† & $\begin{array}{l}\text { Restore pancreatic beta cells ability to secrete insulin } \rightarrow \text { improvement } \\
\text { pancreatic function. }\end{array}$ & Rai et al. (30); 2012. \\
\hline eNOS* & $\begin{array}{l}\text { Suppressing inflammation and productions ROS/RNS in arteries, promoting } \\
\text { blood vessel relaxation } \rightarrow \text { improvement endothelial and cardiovascular } \\
\text { function, ateroprotection. }\end{array}$ & $\begin{array}{l}\text { Mattagajasingh et al. (31); } \\
2010 .\end{array}$ \\
\hline $\mathrm{LXR}^{*}$ & $\begin{array}{l}\text { Decrease triglycerides, total cholesterol and LDL cholesterol, increase HDL } \\
\text { cholesterol } \rightarrow \text { protection against cardiovascular disease. }\end{array}$ & Li et al. (32); 2007. \\
\hline SREBP ${ }^{*}$ & $\begin{array}{l}\text { Reducing hepatic triglyceride synthesis and fat deposition in the liver } \rightarrow \\
\text { protection against non-alcoholic fatty liver disease. }\end{array}$ & Wang et al. (33); 2009. \\
\hline $\begin{array}{l}\operatorname{Atg} 5^{*} \\
\operatorname{Atg} 7^{*} \\
\operatorname{Atg} 8^{*}\end{array}$ & $\begin{array}{l}\text { Breaking down and recycling damaged cellular components } \rightarrow \text { promotion } \\
\text { cellular rejeuvenation. }\end{array}$ & $\begin{array}{l}\text { Chung et al. (34); } 2010 . \\
\text { Ng et al. (22); } 2013 .\end{array}$ \\
\hline CLOCK & Regulation of circadian rhythm. & Chung et al. (34); 2010. \\
\hline c-Myc* & Negatively regulate cell growth and transformation $\rightarrow$ tumour suppression. & $\begin{array}{l}\text { Yuan et al. (35); } 2009 . \\
\text { Haigis et al. (36); } 2010 .\end{array}$ \\
\hline TORC1/CREB* & Neuroprotective role in the pathogenesis of Huntington's disease. & $\begin{array}{l}\text { Jeong et al. (37); } 2011 . \\
\text { Duan (38); } 2013 .\end{array}$ \\
\hline PCAF* & $\begin{array}{l}\text { Controls the E2F1/p73 apoptotic pathway } \rightarrow \text { modulate tumor cell survival and } \\
\text { chemosensitivity. }\end{array}$ & Pediconi et al. (39); 2009. \\
\hline \multicolumn{3}{|c|}{$\begin{array}{l}\text { *deacetylation targets; ttranscriptional targets; ¥binding partners. } \\
\text { FOXO - forkhead box class O; PGC-1a - peroxisome proliferation-activated receptor gamma coactivator-1a; NFKB - nuclear factor-kB; } \\
\text { HIF - hypoxia inducible factor; PPAR - peroxisome proliferation-activated receptor; UCP2 - uncoupling protein gene 2; eNOS - } \\
\text { endothelial nitric oxide synthase; LXR - liver X receptor; SREBP1 - sterol regulatory element binding protein1; Atg-autophagy-related } \\
\text { proteins; CLOCK - circadian locomotor output cycles kaput; TORC1 - transducer of regulated CREB 1; CREB - CAMP responsive } \\
\text { element-binding protein; PCAF - P300/CBP-associated factor. }\end{array}$} \\
\hline
\end{tabular}


thereby emerges from the shadow of SIRT1. SIRT3 is highly expressed in tissues with high oxidative capacity such as liver, heart, skeletal muscle and brown adipose tissue (BAT). It was shown that SIRT3 expression is up-regulated under calorie restriction, exercise and cold exposure which lead to adaptation of different physiological processes in these tissues and organs (Figure 1) (43-45). All this leads to the assumption that cold exposure and physical activity in scuba diving could induce expression of SIRT3. Similarly, it was shown that exercise, caloric restriction and resveratrol (polyphenol from grapes and red wine) are potent SIRT1 activators $(3,46)$, and thus may affect many biological functions of SIRT1 (Figure 2) (47). In support of the above, the comparison of the acute effects of red wine, beer and vodka against hyperoxia-induced oxidative stress (breathing 100\% normobaric oxigen) showed that only red wine provides protection against oxygen-induced oxidative stress (48).
Moreover, study in animal models showed an in crease of the skeletal muscle SIRT1 expression 2 hours after acute endurance exercise and after 14 days of training (49). Studies in humans reported an increase of muscle SIRT1 protein expression after single bout of sprint exercise (50), and an increase in muscle SIRT1 mRNA after single bout and successive bouts of cycling (51). On the other hand, the level of SIRT3 expression in lymphocytes remained unchanged 2 hours after exercise in a hot environment, but was increased after 2 hours of exercise in a cold environment (52). Another study found no change in SIRT3 expression in lymphocytes after intense swimming, but a positive correlation was found between SIRT3 and CAT expression, thus suggesting a close relationship between the expression of these genes in lymphocytes in vivo (53).

Due to increased physical activity, hyperoxia and exposure to cold temperatures, it is considered

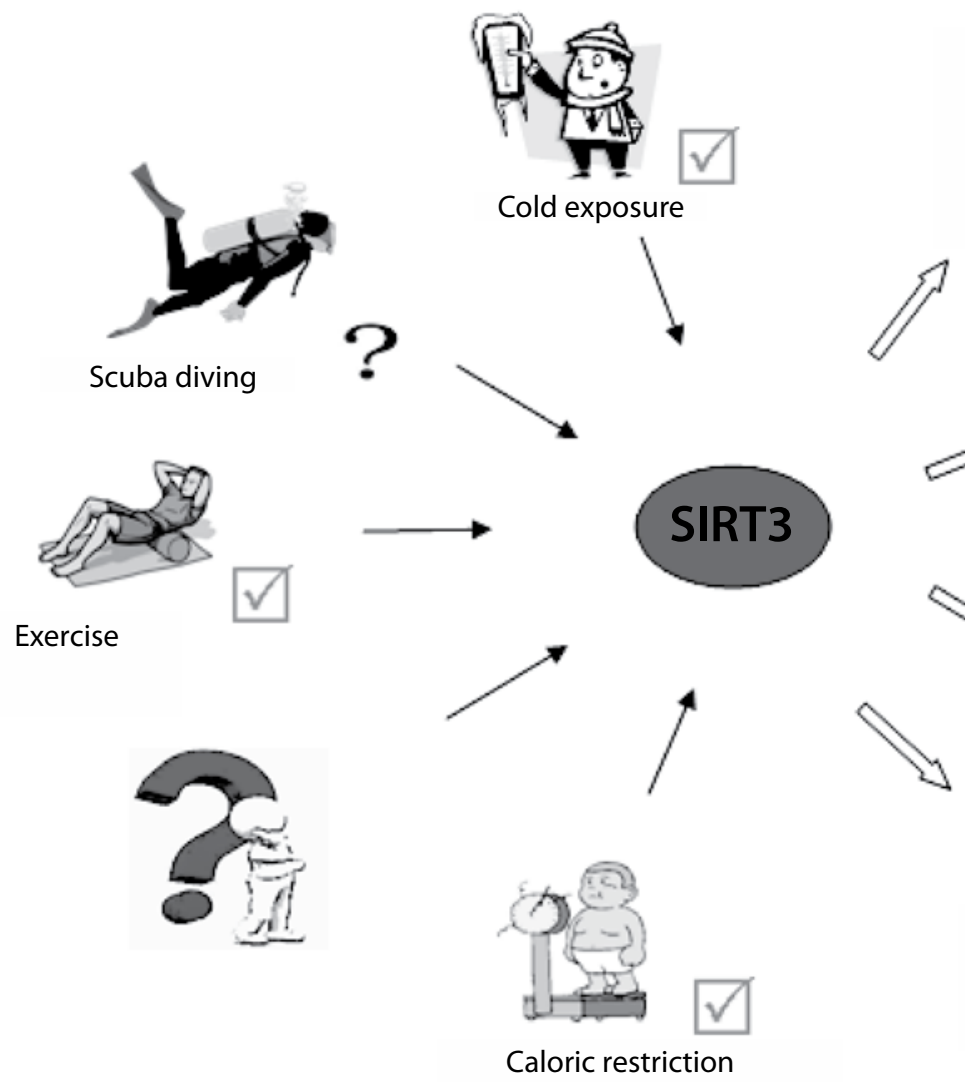

HEART

Protects

cardiomyocytes from

oxidative stress,

Blocks development of cardiac hypertrophy

\section{LIVER}

Regulates fatty acid

oxidation, acetate metabolism, urea cycle, antioxidant pathways

BAT

Regulates mitochondrial

function and thermogenesis

SKELETAL MUSCLE

Increases mitochondrial biogenesis and oxidative capacity, ROS protection

FIGURE 1. Calorie restriction, cold exposure and exercise induce SIRT3 expression and activity in tissues and organs with high oxidative capacity such as heart, liver, skeletal muscle and brown adipose tissue (BAT). Increased expression and activity of SIRT3 is important for the adaptation of different physiological processes in these tissues and organs. 


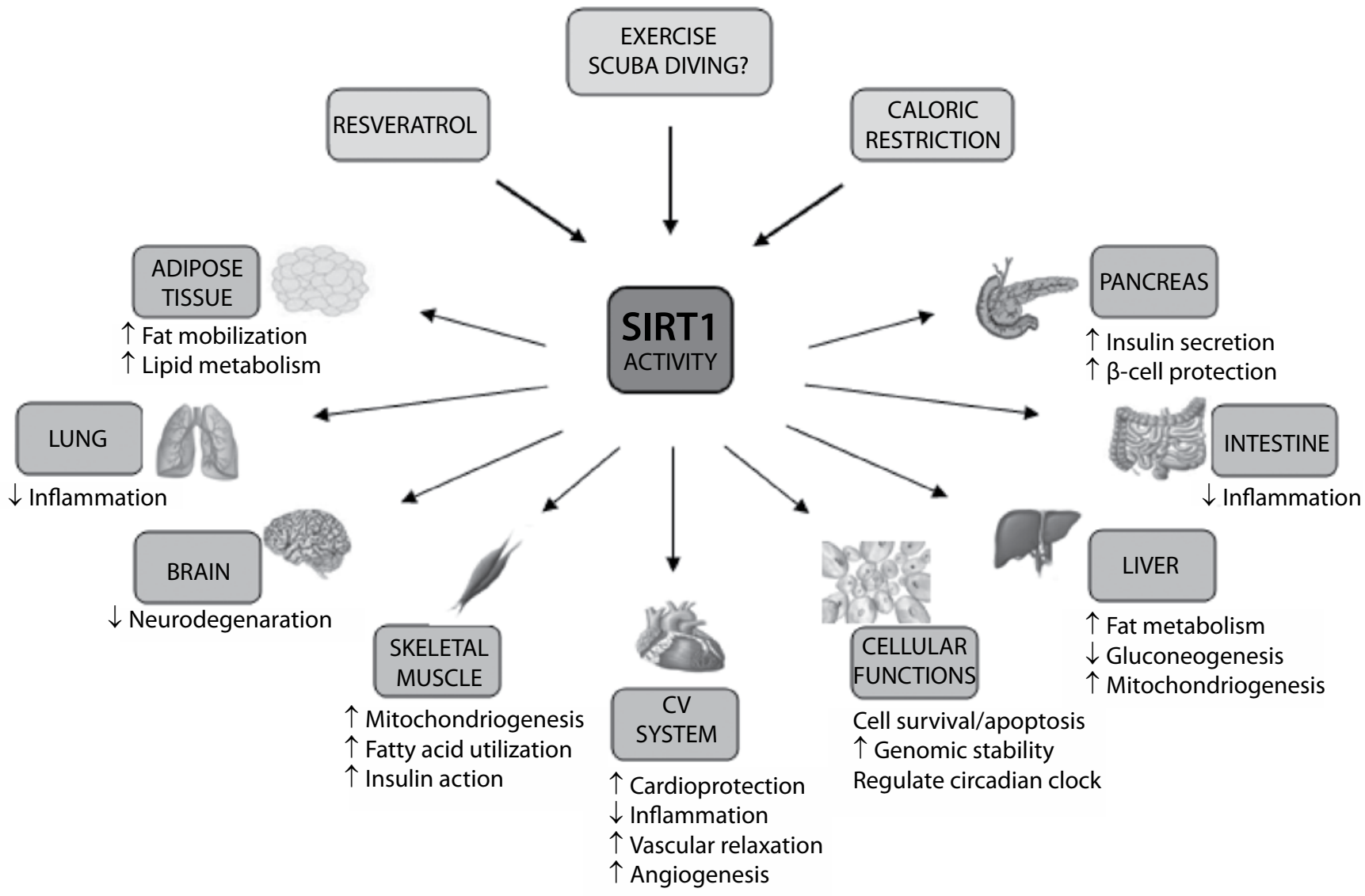

FIGURE 2. Biological functions of SIRT1. Resveratrol, caloric restriction and exercise (scuba diving?) can induce SIRT1, leading to changes of many biological functions in different organs and tissues. CV - cardiovascular.

that scuba diving induces oxidative stress in the human organism. Oxidative stress could have harmful effects related to the free radicals accumulation, but on the other hand, ROS could activate various signalling pathways and the genes expression including SIRTs. It is reasonable to assume that scuba diving-induced oxidative stress increases SIRTs expression which leads to the expression and activation of antioxidant enzymes, but it might change other physiological functions related to SIRTs. Schematic presentation of the potential connection between scuba diving and SIRTs, together with many age-related diseases linked to the activity of SIRTs is shown in Figure 3. Therefore, the question is whether scuba diving increases resistance to oxidative stress and has positive effect on health and lifespan or not.

\section{Cardiovascular response to scuba diving}

During the scuba dive, divers are exposed to numerous factors which may affect haemodynamics and CV function. The mechanisms of CV adaptation during a dive are still unclear, but diving-induced oxidative stress and increase in SIRTs expression could be an important factor. Animal model studies have shown significant increase in SIRT1 and SIRT3 expressions in the heart during stress conditions $(54,55)$ as well as an increase in SIRT1 protein levels in vascular endothelial cells after acute exercise and caloric restriction $(56,57)$. It can be assumed that scuba diving could also induce expression of SIRTs and hence inhibit undesirable CV stress effects. 


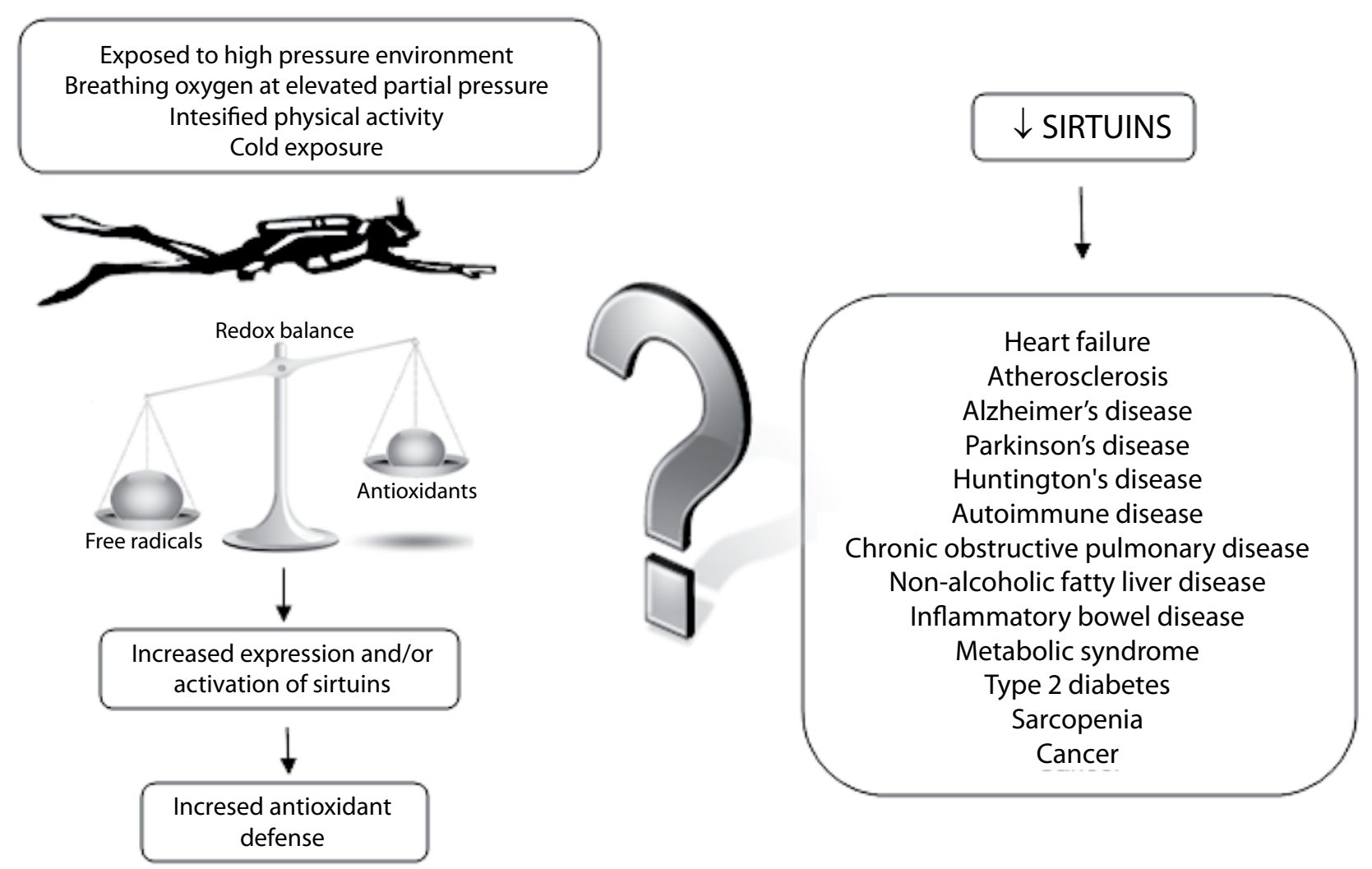

FIGURE 3. Schematic presentation of the potential connection between the increase in ROS production during dives and an increase of expression or activation of sirtuins, along with many age-related diseases linked to the activity of sirtuins.

SIRT1 and SIRT3 protect cardiomyocytes via increase of CAT and SOD2 expression $(54,58)$, but also SIRT1 suppresses inflammatory processes in the heart (59), whilst SIRT3 has an important role in the regulation of cardiac energy metabolism (42). Therefore, SIRTs and their effects provide the mechanisms for cardiac adaption to the stress conditions. Additionally, SIRT1 plays a critical role in regulation of vascular/endothelial homeostasis and remodelling (60); it stimulates angiogenic activity of endothelial cells (61) and stimulates eNOS activity which leads to an increase of nitric oxide (NO) production (31). This indicates that SIRT1 could be an important regulator of the vascular response to scuba diving.

However, whether induced SIRTs expression can have a lasting effect in CV protection, thus representing a prevention of the upcoming harmful effects is still unclear. It should also be taken in consideration that SIRTs through their multiple targets stimulate or suppress many other important CV processes. Although the significant efforts have been invested in identification of mechanisms and agents which could induce the expression and activation of SIRTs, many signalling pathways still remain to be discovered.

Changes in the CV function have been observed after the dive, and many of these changes accompany other types of exercises either for recreational or professional sports. Studies on divers have reported that one single dive as well as successive dives induces alterations in vascular/endothelial function (assessed by imaging tests) $(9,14,62)$. However, it is unclear to what extent these changes in divers are similar or different to the changes in vascular endothelial functions observed in other professional or recreational athletes. (63). Recent studies have shown an increase in NO production (assessed by plasma nitrite levels) 3 hours after diving $(7,8)$ and decrease in plasma endothelin-1 (ET-1) concentration immediately and 3 hours after diving, whilst vascular endothelial growth factor 
(VEGF) concentration increased after diving and returned to initial values 3 hours after diving (8). VEGF is a major contributor to the angiogenesis and up-regulation of VEGF is an important component of the physiological response to exercise. Increase of NO, as a major vasodilator and reduction of ET-1, a powerful vasoconstrictor, has positive effects on the CV system. Therefore, these data indicate protective effects of scuba diving on vascular disorders in whose background are possible SIRTs. On the other hand, two other studies found no difference in levels of plasma nitrite (14) and plasma ET-1 (64) before and after successive dives. The possible causes of the observed discrepancies are differences between the study design and differences between the used tests.

In addition to the aforementioned asymptomatic changes of cardiovascular function, several studies have shown an increase in levels of B-type natriuretic peptide (BNP) and $\mathrm{N}$-terminal proB-type natriuretic peptide (NT-proBNP) after diving (6567). It is important to mention that a significant increase in BNP or proBNP after exposure to HBO (68) and simulated diving (69), and also even after studying the effects of immersion (70) and exposure to cold (71) was not observed. Considering these data and the fact that numerous studies have shown an increase of BNP levels after exercise (72-76), it is evident that physical activity plays an important role in BNP increase after diving.

Physical activity is obviously one of the key causes of CV stress in divers. However environmental conditions such as hyperoxia, increase in the ambient pressure, cold exposure, effect of immersion, formation of intravascular bubbles and psychological stress present in scuba diving can also contribute to CV stress. An acute exposure to above mentioned conditions can result in cardiovascular disorder and could be fatal. On the other hand, gradual exposure and consequential CV stress can result in improved resistance not only of CV function but also of the whole organism. SIRTs certainly have a major role in the adaptation mechanisms. Still there are no proven strategies to reduce exercise related cardiac events and consequently no proven strategies that could be confidently applied to diving.
Thus, at the end the question remains: whether and if yes, under which circumstances, scuba diving improves or deteriorates CV function, and which mechanisms are involved in this story? We hope that future research will be able to offer the answers.

\section{Future directions and perspectives}

Scuba diving-induced oxidative stress is an interesting and still largely unexplored area. SIRTs, "molecular traffic lights in the crossroad of oxidative stress" (20), due to their connection with the extended lifespan have "celebrity" status in the research field of aging and many aging-related diseases (24). Although numerous studies have given a great contribution to the role and the significance of SIRTs in exercise-induced oxidative stress, still, there is no a single study on SIRTs in scuba diving. Scuba diving represents one of the possible models which include mechanisms that can increase the expression and activation of SIRTs. However, it remains unclear how environmental conditions under water may contribute to the increased expression or activation of SIRTs. Similarly, little is known on how production of free radicals depends on the diving depth and the duration of exposure to high pressure environment, cold as well as the type of breathing gas (air, nitrox, trimix etc). It should be mentioned that diving with the nitrox due to lower ratio of nitrogen, compared with the air, reduces the possibility of gas bubble formation as well as the risk of diving DCS. This effect accelerates decompression and extends the diving time, which results in growing popularity of recreational scuba diving with nitrox as opposed to scuba diving using air. However, nitrox diving has a potential, but not sufficiently explored negative side which is associated to the exposure to higher oxygen pressure in contrast to air diving (14). Therefore, the unexplored questions are: a) what happens to the formation of free radicals, antioxidant defence enzymes, CV biomarkers and SIRTs after the intense physical activity under water; b) what happens in the same conditions but without the increased physical activity and c) what happens in the same conditions but with using different breathing gases. 
Regular exercise leads to the upregulation of the antioxidant defence, which helps to reduce oxidative stress that can occur after acute exercise (2). So, one of the important aspects of scuba diving, as well as of other forms of exercise, is its frequency. Measurements of oxidative damage markers and other parameters linked to the oxidative and CV stress following the repeated dives, may offer valuable information on how often scuba diving should or should not be practiced. Additionally, due to the increasing popularity of scuba diving and the growing prevalence of CV diseases in the world, the impact of diving on CV function is very important $(77,78)$. Research in this direction could provide a powerful tool for medical evaluation of potential divers.

Differences in the design of research studies on exercise-induced oxidative stress represent a huge problem in the evaluation of their results. Furthermore, measurement of different markers of oxidative damage, antioxidant defence enzymes and CV biomarkers, as well as the differences in the used tests and the sampling time after the exercise, all pose another difficulty in making reliable inferences in the research of exercise-induced oxidative stress. In future, defining standardized guidelines and recommendations for the studies dealing with exercise-induced stress, will be needed.

\section{References}

1. CMAS, Universal standards and procedures. Available at: http://www.cmas.org/technique/general-documents. Accessed December 23th, 2013.

2. Gomes EC, Silva AN, de Oliveira MR. Oxidants, antioxidants, and the beneficial roles of exercise-induced production of reactive species. Oxid Med Cell Longev 2012;2012:756132. http://dx.doi.org/10.1155/2012/756132.

3. Corbi $G$, Conti V, Russomanno $G$, Rengo $G$, Vitulli $P$, Ciccarelli $A L$, et al. Is physical activity able to modify oxidative damage in cardiovascular aging? Oxid Med Cell Longev 2012;2012:728547.

4. Salminen A, Kaarniranta K, Kauppinen A. Crosstalk between oxidative stress and SIRT1: impact on the aging process. Int J Mol Sci 2013;14:3834-59. http://dx.doi.org/10.3390/ ijms 14023834 .

5. Doubt TJ. Cardiovascular and thermal responses to SCUBA diving. Med Sci Sports Exerc 1996;28:581-6.

\section{Conclusion}

Scuba diving represents a special form of exerciseinduced oxidative stress, in which increased production of free radicals occurs not only due to increased physical activity, but also due to the changes in the environmental conditions under the water. Precisely, these additional environmental aspects represent diving as an interesting and unexplored field of exercise-induced oxidative stress.

The discovery of new signalling pathways and molecules such as SIRTs opens up new areas of redox biology that show negative but also positive effects of oxidative stress, as well as the connection of oxidative stress with aging and age-related diseases. Although intensive studies in the recent years have provided many answers about exerciseinduced oxidative and CV stress, there are still a lot of questions and contradictions, especially related to various forms of recreational or professional sports, including scuba diving.

\section{Potential conflict of interest}

None declared.

6. Ferrer MD, Sureda A, Batle JM, Tauler P, Tur JA, Pons A. Scuba diving enhances endogenous antioxidant defenses in lymphocytes and neutrophils. Free Radic Res 2007;41:27481. http://dx.doi.org/10.1080/10715760601080371.

7. Sureda A, Ferrer MD, Batle JM, Tauler P, Tur JA, Pons A. Scuba diving increases erythrocyte and plasma antioxidant defenses and spares NO without oxidative damage. Med Sci Sports Exerc 2009;41:1271-6. http://dx.doi.org/10.1249/ MSS.0b013e3181951069.

8. Sureda A, Batle JM, Ferrer MD, Mestre-Alfaro A, Tur JA, Pons A. Scuba diving activates vascular antioxidant system. Int J Sports Med 2012;33:531-6. http://dx.doi.org/10.1055/s0031-1297957.

9. Obad A, Marinovic J, Ljubkovic M, Breskovic T, Modun D, Boban M, Dujic Z. Successive deep dives impair endothelial function and enhance oxidative stress in man. Clin Physiol Funct Imaging 2010;30:432-8. http://dx.doi.org/10.1111/ j.1475-097X.2010.00962.x. 
10. Vince RV, McNaughton LR, Taylor L, Midgley AW, Laden $G$, Madden LA. Release of VCAM-1 associated endothelial microparticles following simulated SCUBA dives. Eur J Appl Physiol 2009;105: 507-13. http://dx.doi.org/10.1007/ s00421-008-0927-z.

11. Morabito C, Bosco G, Pilla R, Corona C, Mancinelli R, Yang $Z$, et al. Effect of pre-breathing oxygen at different depth on oxidative status and calcium concentration in lymphocytes of scuba divers. Acta Physiol 2011;202:69-78. http://dx.doi. org/10.1111/j.1748-1716.2010.02247.x.

12. Obad A, Palada I, Valic $Z$, Ivancev $V$, Baković $D$, Wisløff $U$, et al. The effects of acute oral antioxidants on diving-induced alterations in human cardiovascular function. J Physiol 2007;578:859-70. http://dx.doi.org/10.1113/ jphysiol.2006.122218.

13. Obad A, Valic Z, Palada I, Brubakk AO, Modun D, Dujić $Z$. Antioxidant pretreatment and reduced arterial endothelial dysfunction after diving. Aviat Space Environ Med 2007;78:1114-20. http://dx.doi.org/10.3357/ ASEM.2039.2007.

14. Marinovic J, Ljubkovic M, Breskovic T, Gunjaca G, Obad $A$, Modun $D$, et al. Effects of successive air and nitrox dives on human vascular function. Eur J Appl Physiol 2012;112:2131-7. http://dx.doi.org/10.1007/s00421-0112187-6.

15. Brubakk AO, Duplancic D, Valic Z, Palada I, Obad A, Bakovic $D$, et al. A single air dive reduces arterial endothelial function in man. J Physiol 2005;566:901-6. http://dx.doi. org/10.1113/jphysiol.2005.089862.

16. Alleva R, Nasole E, Di Donato F, Borghi B, Neuzil J, Tomasetti M. Alpha-Lipoic acid supplementation inhibits oxidative damage, accelerating chronic wound healing in patients undergoing hyperbaric oxygen therapy. Biochem Biophys Res Commun 2005;333:404-10. http://dx.doi.org/10.1016/j. bbrc.2005.05.119.

17. Dujic Z, Duplancic D, Marinovic-Terzic I, Bakovic D, Ivancev $V$, Valic $Z$, et al. Aerobic exercise before diving reduces venous gas bubble formation in humans. J Physiol 2004;555:63742. http://dx.doi.org/10.1113/jphysiol.2003.059360.

18. Dujić $Z$, Palada I, Obad A, Duplancić D, Baković D, Valic Z. Exercise during a 3-min decompression stop reduces postdive venous gas bubbles. Med Sci Sports Exerc 2005;37:131923. $h$ ttp://dx.doi.org/10.1113/jphysiol.2003.059360.

19. Dujić Z, Obad A, Palada I, Ivancev V, Valic Z. Venous bubble count declines during strenuous exercise after an open sea dive to 30 m. Aviat Space Environ Med 2006;77:592-6.

20. Rajendran $R$, Garva R, Krstic-Demonacos $M$, Demonacos $C$. Sirtuins: molecular traffic lights in the crossroad of oxidative stress, chromatin remodeling, and transcription. J Biomed Biotechnol 2011;368276.

21. Shah ZH, Ahmed SU, Ford JR, Allison SJ, Knight JR, Milner J. A deacetylase-deficient SIRT1 variant opposes $f u-$ II-length SIRT1 in regulating tumor suppressor p53 and governs expression of cancer-related genes. Mol Cell Biol 2012;32:704-16. http://dx.doi.org/10.1128/MCB.06448-11.

22. Ng F, Tang BL. Sirtuins' modulation of autophagy. J Cell Physiol 2013;228:2262-70. http://dx.doi.org/10.1002/ jcp.24399.
23. Luo J, Nikolaev AY, Imai S, Chen D, Su F, Shiloh A, et al. Negative control of $p 53$ by Sir2alpha promotes cell survival under stress. Cell 2001;107:137-48. http://dx.doi.org/10.1016/ S0092-8674(01)00524-4.

24. Webster BR, Lu Z, Sack MN, Scott I. The role of sirtuins in modulating redox stressors. Free Radic Biol Med 2012;52:28190.http://dx.doi.org/10.1016/j.freeradbiomed.2011.10.484.

25. Nemoto S, Fergusson MM, Finkel T. SIRT1 functionally interacts with the metabolic regulator and transcriptional coactivator PGC-1a. J Biol Chem 2005;280:16456-60. http:// dx.doi.org/10.1074/jbc.M501485200.

26. Kauppinen A, Suuronen T, Ojala J, Kaarniranta K, Salminen A. Antagonistic crosstalk between NF-KB and SIRT1 in the regulation of inflammation and metabolic disorders. Cell Signal 2013;25:1939-48. http://dx.doi.org/10.1016/j. cellsig.2013.06.007.

27. Baur JA. Biochemical effects of SIRT1 activators. Biochim Biophys Acta 2010;1804:1626-34. http://dx.doi.org/10.1016/j. bbapap.2009.10.025.

28. Tang BL. Sirt1 and cell migration. Cell Adh Migr 2010;4:163-5. http://dx.doi.org/10.4161/cam.4.2.10972.

29. Jeong J, Juhn $K$, Lee $H$, Kim SH, Min BH, Lee KM, et al. SIRT1 promotes DNA repair activity and deacetylation of Ku70. Exp Mol Med 2007;39:8-13. http://dx.doi.org/10.1038/ emm.2007.2.

30. Rai E, Sharma S, Kaul S, Jain K, Matharoo K, Bhanwer AS, Bamezai RN. The interactive effect of SIRT1 promoter region polymorphism on type 2 diabetes susceptibility in the North Indian population. PLoS One 2012;7:e48621. http:// dx.doi.org/10.1371/journal.pone.0048621.

31. Mattagajasingh I, Kim CS, Naqvi A, Yamamori T, Hoffman TA, Jung SB, et al. SIRT1 promotes endothelium-dependent vascular relaxation by activating endothelial nitric oxide synthase. Proc Natl Acad Sci USA 2007;104:14855-60. http://dx.doi.org/10.1073/pnas.0704329104.

32. Li X, Zhang S, Blander G, Tse JG, Krieger M, Guarente L. SIRT1 deacetylates and positively regulates the nuclear receptor LXR. Mol Cell 2007;28:91-106. http://dx.doi.org/10.1016/j. molcel.2007.07.032.

33. Wang GL, Fu YC, Xu WC, Feng YQ, Fang SR, Zhou XH. Resveratrol inhibits the expression of SREBP1 in cell model of steatosis via Sirt1-FOXO1 signaling pathway. Biochem Biophys Res Commun 2009;380:644-9. http://dx.doi.org/10.1016/j. bbrc.2009.01.163.

34. Chung S, Yao H, Caito S, Hwang J, Arunachalam G, Rahman I. Regulation of SIRT1 in cellular functions: role of polyphenols. Arch Biochem Biophys 2010;501:79-90. http:// dx.doi.org/10.1016/j.abb.2010.05.003.

35. Yuan J, Minter-Dykhouse K, Lou Z. A c-Myc-SIRT1 feedback loop regulates cell growth and transformation. J Cell Biol 2009;185:203-11. http://dx.doi.org/10.1083/ jcb.200809167.

36. Haigis MC, Sinclair DA. Mammalian sirtuins: biological insights and disease relevance. Annu Rev Pathol 2010;5:253-95. http://dx.doi.org/10.1146/annurev.pathol.4.110807.092250. 
37. Jeong $H$, Cohen DE, Cui L, Supinski A, Savas JN, Mazzulli $J R$ et al. Sirt1 mediates neuroprotection from mutant huntingtin by activation of the TORC1 and CREB transcriptional pathway. Nat Med 2011;18:159-65. http://dx.doi. org/10.1038/nm.2559.

38. Duan W. Targeting sirtuin-1 in Huntington's disease: rationale and current status. CNS Drugs 2013;27:345-52. http:// dx.doi.org/10.1007/s40263-013-0055-0.

39. Pediconi N, Guerrieri F, Vossio S, Bruno T, Belloni L, Schinzari $V$ et al. hSirT1-dependent regulation of the PCAFE2F1-p73 apoptotic pathway in response to DNA damage. Mol Cell Biol 2009;29:1989-98. http://dx.doi.org/10.1128/ MCB.00552-08.

40. Lombard DB, Tishkoff $D X$, Bao J. Mitochondrial sirtuins in the regulation of mitochondrial activity and metabolic adaptation. Handb Exp Pharmacol 2011;206:163-88. http://dx.doi.org/10.1128/MCB.00552-08.

41. Chen Y, Zhang J, Lin Y, Lei Q, Guan KL, Zhao S, Xiong Y. Tumour suppressor SIRT3 deacetylates and activates manganese superoxide dismutase to scavenge ROS. EMBO Rep 2011;12:534-41. http://dx.doi.org/10.1038/embor.2011.65.

42. Schlicker C, Gertz M, Papatheodorou P, Kachholz B, Becker CF, Steegborn $C$. Substrates and regulation mechanisms for the human mitochondrial sirtuins Sirt3 and Sirt5. J Mol Biol 2008;382:790-801. http://dx.doi.org/10.1016/j. jmb.2008.07.048.

43. Shi T, Wang F, Stieren E, Tong Q. SIRT3, a mitochondrial sirtuin deacetylase, regulates mitochondrial function and thermogenesis in brown adipocytes. J Biol Chem 2005;280:13560-7. http://dx.doi.org/10.1074/jbc. M414670200.

44. Giralt A, Villarroya F. SIRT3, a pivotal actor in mitochondrial functions: metabolism, cell death and aging. Biochem J 2012;444:1-10. http://dx.doi.org/10.1042/BJ20120030.

45. Palacios OM, Carmona JJ, Michan S, Chen KY, Manabe $Y$, Ward $J$, et al. Diet and exercise signals regulate SIRT3 and activate AMPK and PGC-1a in skeletal muscle. Aging 2009;1:771-83.

46. Chung JH, Manganiello V, Dyck JR. Resveratrol as a calorie restriction mimetic: therapeutic implications. Trends Cell Biol 2012;22:546-54. http://dx.doi.org/10.1016/j. tcb.2012.07.004.

47. Bao J, Sack MN. Protein deacetylation by sirtuins: delineating a post-translational regulatory program responsive to nutrient and redox stressors. Cell Mol Life Sci 2010;67:307387. http://dx.doi.org/10.1007/s00018-010-0402-y.

48. Krnic M, Modun D, Budimir D, Gunjaca G, Jajic I, Vukovic J, et al. Comparison of acute effects of red wine, beer and vodka against hyperoxia-induced oxidative stress and increase in arterial stiffness in healthy humans. Atherosclerosis 2011;218:530-5. http://dx.doi.org/10.1016/j. atherosclerosis.2011.07.004.

49. Suwa M, Nakano H, Radak Z, Kumagai S. Endurance exercise increases the SIRT1 and peroxisome proliferator-activated receptor gamma coactivator-1alpha protein expressions in rat skeletal muscle. Metabolism 2008;57:986-98. http://dx.doi.org/10.1016/j.metabol.2008.02.017.
50. Guerra B, Guadalupe-Grau A, Fuentes T, Ponce-González $J G$, Morales-Alamo D, Olmedillas $H$, et al. SIRT1, AMP-activated protein kinase phosphorylation and downstream $\mathrm{ki}$ nases in response to a single bout of sprint exercise: influence of glucose ingestion. Eur J Appl Physiol 2010;109:73143. http://dx.doi.org/10.1007/s00421-010-1413-y.

51. Dumke CL, Mark Davis J, Angela Murphy E, Nieman DC, Carmichael MD, Quindry JC, et al. Successive bouts of cycling stimulates genes associated with mitochondrial biogenesis. Eur J Appl Physiol 2009;107:419-27. http://dx.doi. org/10.1007/s00421-009-1143-1.

52. Mestre-Alfaro A, Ferrer MD, Banquells $M$, Riera J, Drobnic $F$, Sureda $A$, et al. Body temperature modulates the antioxidant and acute immune responses to exercise. Free Radic Res 2012;46:799-808. http://dx.doi.org/10.3109/10715762. 2012.680193.

53. Ferrer MD, Tauler P, Sureda A, Tur JA, Pons A. Antioxidant regulatory mechanisms in neutrophils and lymphocytes after intense exercise. J Sports Sci 2009;27:49-58. http://dx.doi. org/10.1080/02640410802409683.

54. Alcendor RR, Gao S, Zhai P, Zablocki D, Holle E, Yu X, et al. Sirt1 regulates aging and resistance to oxidative stress in the heart. Circ Res 2007;100:1512-21. http://dx.doi. org/10.1161/01.RES.0000267723.65696.4a.

55. Sundaresan NR, Samant SA, Pillai VB, Rajamohan SB, Gupta MP. SIRT3 is a stress-responsive deacetylase in cardiomyocytes that protects cells from stress-mediated cell death by deacetylation of Ku70. Mol Cell Biol 2008;28:6384401. http://dx.doi.org/10.1128/MCB.00426-08.

56. CacicedoJM, GauthierMS, LebrasseurNK, Jasuja R, Ruderman $N B$, Ido Y. Acute exercise activates AMPK and eNOS in the mouse aorta. Am J Physiol Heart Circ Physiol 2011;301:H125565. http://dx.doi.org/10.1152/ajpheart.01279.2010.

57. Rippe C, Lesniewski L, Connell M, LaRocca T, Donato A, Seals $D$. Short-term calorie restriction reverses vascular endothelial dysfunction in old mice by increasing nitric oxide and reducing oxidative stress. Aging Cell 2010;9:304-12. http://dx.doi.org/10.1111/j.1474-9726.2010.00557.x.

58. Sundaresan NR, Gupta M, Kim G, Rajamohan SB, Isbatan A, Gupta MP. Sirt3 blocks the cardiac hypertrophic response by augmenting Foxo3a-dependent antioxidant defense mechanisms in mice. J Clin Invest 2009;119:2758-71.

59. Palomer $X$, Salvadó $L$, Barroso E, Vázquez-Carrera M. An overview of the crosstalk between inflammatory processes and metabolic dysregulation during diabetic cardiomyopathy. Int J Cardiol 2013;168:3160-72. http://dx.doi. org/10.1016/j.ijcard.2013.07.150.

60. Potente M, Dimmeler S. Emerging roles of SIRT1 in vascular endothelial homeostasis. Cell Cycle 2008;7:2117-22. http:// dx.doi.org/10.4161/cc.7.14.6267.

61. Potente M, Ghaeni L, Baldessari D, Mostoslavsky R, Rossig L, Dequiedt $F$, et al. SIRT1 controls endothelial angiogenic functions during vascular growth. Genes Dev 2007;21:264458. http://dx.doi.org/10.1101/gad.435107.

62. Lambrechts K, Pontier JM, Balestra C, Mazur A, Wang $Q$, Buzzacott $P$, et al. Effect of a single, open-sea, air scuba dive on human micro- and macrovascular function. Eur $J$ Appl Physiol 2013;113:2637-45. http://dx.doi.org/10.1007/ s00421-013-2676-X. 
63. Miyachi M. Effects of resistance training on arterial stiffness: a meta-analysis. Br J Sports Med 2013;47:393-6. http:// dx.doi.org/10.1136/bjsports-2012-090488.

64. Bilopavlovic N, Marinovic J, Ljubkovic M, Obad A, Zanchi $J$, Pollock NW, et al. Effect of repetitive SCUBA diving on humoral markers of endothelial and central nervous system integrity. Eur J Appl Physiol 2013;113:1737-43. http:// dx.doi.org/10.1007/s00421-013-2600-4.

65. Gempp E, Blatteau JE, Louge P, Drouillard I, Galland FM. $N$-terminal pro brain natriuretic peptide increases after 1 - $h$ scuba dives at $10 \mathrm{~m}$ depth. Aviat Space Environ Med 2005;76:114-6.

66. Marinovic J, Ljubkovic M, Obad A, Breskovic T, Salamunic I, Denoble PJ, et al. Assessment of extravascular lung water and cardiac function in trimix SCUBA diving. Med SCi Sports Exerc 2010;42:1054-61.

67. Passino C, Franzino E, Giannoni A, Prontera C, Goetze JP, Emdin $M$, Clerico A. B-type natriuretic peptide secretion following scuba diving. Biomark Med 2011;5:205-9. http:// dx.doi.org/10.2217/bmm.11.14.

68. Grassi P, Buscema G, Rinaldi A, Gobbato PE, Berlot G. Btype natriuretic peptide in healthy subjects after exposure to hyperbaric oxygen at 2.5 ATA. Aviat Space Environ Med 2007;78:52-3.

69. Grassi P, Stenner E, Rinaldi A, Delbello G, Piccinini C, Bussani $A$, et al. B-type natriuretic peptide after open-water and hyperbaric chamber exposure to $10 \mathrm{msw}$. Aviat Space Environ Med 2009;80:716-9. http://dx.doi.org/10.3357/ ASEM.2544.2009.

70. Kurabayashi H, Tamura K, Tamura J, Kubota K. The effects of hydraulic pressure on atrial natriuretic peptide during rehabilitative head-out water immersion. Life Sci 2001;69:101721. http://dx.doi.org/10.1016/S0024-3205(01)01193-6.
71. Banfi G, Lombardi G, Colombini A, Melegati G. Whole-body cryotherapy in athletes. Sports Med 2010;40:509-17. http:// dx.doi.org/10.2165/11531940-000000000-00000.

72. Scharhag J, Urhausen A, Schneider G, Herrmann M, Schumacher $K$, Haschke $M$, et al. Reproducibility and clinical significance of exercise-induced increases in cardiac troponins and N-terminal pro brain natriuretic peptide in endurance athletes. Eur J Cardiovasc Prev Rehabil 2006;13:38897.

73. Corsetti $R$, Lombardi $G$, Barassi A, Lanteri P, Colombini $A$, $D^{\prime}$ Eril GM, Banfi G. Cardiac indexes, cardiac damage biomarkers and energy expenditure in professional cyclists during the Giro d'Italia 3-weeks stage race. Biochem Med 2012;22:237-46. http://dx.doi.org/10.11613/BM.2012.026.

74. Hadzovic-Dzuvo A, Valjevac A, Avdagić N, Lepara O, Zaćiragić $A$, Jadrić $R$ et al. B-type natriuretic peptide (BNP) serum levels in rats after forced repeated swimming stress. Med Glas 2011;8:121-5.

75. Krupička J, Janota T, Kasalova Z, Hradec J. Effect of shortterm maximal exercise on BNP plasma levels in healthy individuals. Physiol Res 2010;59:625-8.

76. McLachlan C, Mossop P. Are elevations of N-terminal probrain natriuretic peptide in endurance athletes after prolonged strenuous exercise due to systemic inflammatory cytokines? Am Heart J 2006;152:e1. http://dx.doi.org/10.1016/j. ahj.2006.03.022.

77. Muth CM, Tetzlaff K. [Scuba diving and the heart. Cardiac aspects of sport scuba diving]. Herz2004;29:406-13. (in German). http://dx.doi.org/10.1016/j.ahj.2006.03.022.

78. Bove AA. The cardiovascular system and diving risk. Undersea Hyperb Med 2011;38:261-9. 